УДК 549.67:544.478: 66.095.253: 547.532:547.313.2

DOI: $10.33184 /$ bulletin-bsu-2020.1.15

СИНТЕЗ ГРАНУЛИРОВАННОГО ЦЕОЛИТА NaY ВЫСОКОЙ СТЕПЕНИ КРИСТАЛЛИЧНОСТИ

() Д. А. Шавалеев ${ }^{1}$, М. Л. Павлов ${ }^{2}$, Р. А. Басимова ${ }^{2}$, О. С. Травкина $^{3,4}$, И. Н. Павлова ${ }^{3,4}$, Л. Ф. Габдураманова ${ }^{4}$, И. Е. Алехина ${ }^{5}$

${ }^{l} \mathrm{OOO} \ll \mathrm{SNH}$ Group»

Россия, Республика Башкортостан, 453261 г. Салават, ул. Гагарина, 8.

${ }^{2}$ ООО «НТЦ Газпром нефтехим Салават»

Россия, Республика Башкортостан, 453256 г. Салават, ул. Молодогвардейцев, 30.

${ }^{3}$ Институт нефтехимии и катализа РАН

Россия, Республика Башкортостан, 450075 г. Уфа, пр. Октября, 141.

${ }^{4}$ Уфимский государственньй нефтяной технический университет

Россия, Республика Башкортостан, 450062 г. Уфа, ул. Космонавтов, 1.

${ }^{5}$ Башкирский государственный университет

Россия, Республика Башкортостан, 450076 г. Уфа, ул. Заки Валиди, 32.

*Email:28pml@snos.ru

Разработан способ синтеза гранулированного иеолита NaY высокой степени кристалличности с достаточно развитой вторичной пористой структурой, с адсорбционной емкостью, сопоставимой с порошкообразным иеолитом того же типа, и механической прочностью 2.5-2.9 кг/мм². Способ основан на гидротермальной кристаллизации гранул, полученных смешением порошкообразного цеолита $\mathrm{NaY}$, «белой» сажи (молотого силикагеля или аэросила) и каолина, из реакиионных смесей следующего состава: (2.2-2.6) $\mathrm{Na}_{2} \mathrm{O} \cdot \mathrm{Al}_{2} \mathrm{O}_{3} \cdot(6.5-7.5) \mathrm{SiO}_{2} \cdot(155-165) \mathrm{H}_{2} \mathrm{O}$.

Ключевые слова: иеолит NaY, кристаллизация, высокая степень кристалличности, адсорбиионная емкость, механическая прочность.

\section{Введение}

Цеолитсодержащие материалы широко используются в промышленных гетерогенно-каталитических процессах [1]. Одним из таких синтетических цеолитов является цеолит $\mathrm{NaY}$ [2]. Его широкое применение в качестве катализатора обусловлено наличием кислотных центров и развитой пористой структурой. Основная область его применения - катализаторы крекинга. Цеолит Y в Н-форме также является активным компонентом современных катализаторов таких промышленных процессов как гидрокрекинг, гидроизомеризация н-парафинов, изомеризация ксилолов, диспропорционирование и деалкилирование толуола и др. [3-9].

Синтетические цеолиты, пористая структура которых состоит только из микропор, недостаточно эффективны в реакциях между молекулами, имеющими размеры более $10 \AA$, из-за пространственных ограничений. Эту проблему можно решить путем создания материалов с развитой вторичной пористой структурой, обеспечивающей эффективную диффузию как реагентов, так и продуктов реакции внутри зерна катализатора [10-13].

Из литературных данных известны способы синтеза гранулированного цеолита $\mathrm{NaY}$ (тип FAU), не содержащего связующих веществ [14-19]. Способы основаны на кристаллизации гранул, полученных смешением порошкообразного цеолита $\mathrm{NaY}$, молотого силикагеля или «белой» сажи, каолина и пластификатора (поливини-ловый спирт, карбоксиметилцеллюлоза или лигносульфанат) в растворе силиката натрия. Порошкообразный цеолит, входящий в состав исходных гранул, выполняет роль кристаллической затравки, обеспечивающей высокую степень кристалличности и фазовую чистоту образующихся поликристаллических сростков.

Настоящая работа является развитием ранее выполненных исследований [5-9] и посвящена разработке, перспективного для промышленного внедрения, способа получения гранулированного цеолита $\mathrm{NaY}$ (NaY-БC) с высокими адсорбционными характеристиками и механической прочностью.

\section{Объекты и методы исследований}

В экспериментах по получению исходных гранул для кристаллизации использовали каолин марки КЭ-3 (ГОСТ 21286-82), «белую» сажу марки БС-100 (ГОСТ 18307-78), поливиниловый спирт (ГОСТ 10779-97) и порошкообразный цеолит NaY (предельная адсорбционная емкость по парам воды и бензола равна 0.30 и $0.32 \mathrm{~cm}^{3} / \Gamma$, соответственно). Массовое содержание компонентов в составе исходных гранул изменяли в интервалах:

порошкообразный цеолит NaY $\quad$ 50-80\% масс.; каолин (КЭ-3) $15-45 \%$ мacc.;

«белая» сажа (БС)

(молотый силикагель или аэросил) 1-10\% масс.; поливиниловый спирт (ПВС) $2 \%$ масс.

Полученную смесь увлажняли и перемешивали до получения однородной массы, гранулирова- 
ли, подвергали прокалке при $600{ }^{\circ} \mathrm{C}$ в течение 6ч для удаления ПВС. Полученные гранулы кристаллизовали в растворе силиката натрия. Состав реакционной смеси (РС) изменяли в интервалах: (1.9-3.2) $\quad \mathrm{Na}_{2} \mathrm{O} \cdot \mathrm{Al}_{2} \mathrm{O}_{3} \cdot(6.0-7.5) \mathrm{SiO}_{2} \cdot(150-165) \quad \mathrm{H}_{2} \mathrm{O}$, при $98-100{ }^{\circ} \mathrm{C}$ в течение 48 ч. Стадии кристаллизации предшествовала стадия предварительной выдержки гранул при температуре $25-30{ }^{\circ} \mathrm{C}$ в течение $12-24$ ч.

Относительную степень кристалличности (ОСК) и фазовый состав (ФС) образцов определяли с помощью рентгеноструктурного и рентгенофазового анализа (РСА и РФА). РФА образцов проводили на дифрактометре Bruker D8 Advance. Условия съемки: $\mathrm{CuK} \alpha$ излучение, область углов $2 \theta$ от 3 до $50^{\circ}$, шаг - 1 град/мин, время накопления в точке составляло 2 с. Обработку рентгенограмм проводили в программе TOPAS и Eva с привлечением базы данных PDF2.

Объем макропор и их распределение по размеру измеряли на ртутном порозиметре Carlo Erba Porosimeter-2000 [20].

Значения предельной адсорбционной емкости цеолитов определяли по методике, описанной в [21].

\section{Результаты и их обсуждение}

В табл. 1 представлены результаты изучения влияния состава исходных гранул на свойства образцов, полученных после кристаллизации.

Видно, что при содержании в составе исходных гранул 50\% масс. порошкообразного цеолита $\mathrm{NaY}$ образец, полученный после кристаллизации, обладает недостаточно развитой вторичной пористой структурой, низкой степенью кристалличности и предельной адсорбционной емкостью (табл. 1, обр. 1). Причиной этого является отсутствие в исходных гранулах развитой мезо- и макропористой структуры, что затрудняет диффузию кристаллизационного раствора внутрь гранулы. Кроме того, уменьшение кристаллической затравки в составе исходных гранул не способствует образованию при кристаллизации достаточного количества мезопор.

Увеличение содержания порошкообразного цеолита $\mathrm{NaY}$ в составе исходных гранул свыше $70 \%$ масс. приводит к снижению механической прочности самих исходных гранул и образованию при всех последующих операциях значительного количества крошки. Оставшиеся целыми после кристаллизации, отмывки и сушки гранулы обладают так же низкой механической прочностью (табл. 1, обр. 8). Причиной этого является недостаточное содержание каолина в исходных гранулах, т.к. только каолин обладает реологическими свойствами и обеспечивает плотную упаковку компонентов смеси при её грануляции.

После кристаллизации гранулы, в которых содержание белой сажи в исходном составе было менее 3.0\% масс., имеют низкие степень кристалличности и адсорбционную емкость, а также ухудшаются параметры вторичной пористой структуры (табл. 1, обр. 6). Увеличение содержания белой сажи в составе исходных гранул более 7\% масс. снижает механическую прочность гранул после кристаллизации (табл. 1, обр. 5).

Результаты изучения влияния источника кремния в составе исходных гранул на физикохимические характеристики гранулированных образцов после кристаллизации приведены в табл. 2.

Видно, что природа кремнесодержащего сырья, используемого для получения исходных гранул, не влияет на степень кристалличности образцов NaY-БС, их адсорбционные и прочностные характеристики.

В табл. 3 представлены результаты исследования влияния состава реакционной смеси на физикохимические характеристики гранулированных образцов $\mathrm{NaY-БC.}$

Таблица 1

Физико-химические свойства гранулированных образцов после кристаллизации*

\begin{tabular}{|c|c|c|c|c|c|c|c|}
\hline \multirow[t]{2}{*}{$\begin{array}{c}\text { Состав исходных гранул } \\
\text { после прокаливания }\end{array}$} & \multicolumn{2}{|c|}{$\begin{array}{c}\text { Предельная адсорб- } \\
\text { ционная емкость } \\
\left(\mathrm{cm}^{3} / \Gamma\right) \text { по парам: }\end{array}$} & \multirow{2}{*}{$\begin{array}{c}\text { ФС по } \\
\text { данным } \\
\text { РФА }\end{array}$} & \multirow[t]{2}{*}{$\begin{array}{l}\text { OCK, } \\
\% \text { отн. }\end{array}$} & \multirow{2}{*}{$\begin{array}{c}\text { Прочность } \\
\text { на раздавли- } \\
\text { вание, } \\
\text { кг/мм² } \\
\end{array}$} & \multicolumn{2}{|c|}{$\begin{array}{c}\text { Распределение пор } \\
\text { по диаметру, \% }\end{array}$} \\
\hline & воды & бензола & & & & $2-50 \mathrm{HM}$ & более $50 \mathrm{Hм}$ \\
\hline $50 \% \mathrm{NaY}+43 \%$ КЭ-3+5\%БС & 0.26 & 0.27 & FAU & 89 & 2.7 & 54.2 & 45.8 \\
\hline $55 \% \mathrm{NaY}+40 \%$ КЭ-3+3\%БС & 0.30 & 0.32 & FAU & 98 & 2.9 & 65.9 & 34.1 \\
\hline $60 \% \mathrm{NaY}+33 \%$ КЭ-3+5\%БС & 0.30 & 0.32 & FAU & 98 & 2.6 & 66.2 & 33.8 \\
\hline $60 \% \mathrm{NaY}+31 \%$ КЭ-3+7\%БС & 0.30 & 0.32 & FAU & 98 & 2.7 & 67.2 & 32.8 \\
\hline $65 \% \mathrm{NaY}+23 \% \mathrm{~K} Э-3+10 \%$ БС & 0.27 & 0.28 & FAU & 90 & 2.4 & 53.3 & 46.7 \\
\hline $65 \% \mathrm{NaY}+32 \% \mathrm{~K} Э-3+1 \%$ БС & 0.27 & 0.29 & FAU & 92 & 2.3 & 52.1 & 47.9 \\
\hline $70 \% \mathrm{NaY}+23 \% \mathrm{~K} Э-3+5 \%$ БС & 0.30 & 0.32 & FAU & 98 & 2.6 & 68.1 & 31.9 \\
\hline $80 \% \mathrm{NaY}+15 \%$ КЭ-3+5\%БС & 0.30 & 0.32 & FAU & 99 & $1.4 * *$ & 65.8 & 34.2 \\
\hline
\end{tabular}


Физико-химические свойства гранулированных образцов после кристаллизации*

\begin{tabular}{|c|c|c|c|c|c|c|c|}
\hline \multirow{2}{*}{$\begin{array}{c}\text { Состав исходных гранул } \\
\text { после прокаливания }\end{array}$} & \multicolumn{2}{|c|}{$\begin{array}{c}\text { Предельная адсорбцион- } \\
\text { ная емкость }\left(\mathrm{cm}^{3} / \Gamma\right) \\
\text { по парам: } \\
\end{array}$} & \multirow{2}{*}{$\begin{array}{c}\text { ФС } \\
\text { по данным } \\
\text { РФА }\end{array}$} & \multirow{2}{*}{$\begin{array}{l}\text { ОСК, } \\
\% \text { отн. }\end{array}$} & \multirow{2}{*}{$\begin{array}{c}\text { Прочность на } \\
\text { раздавливание, } \\
\text { кг/мм }\end{array}$} & \multicolumn{2}{|c|}{$\begin{array}{c}\text { Распределение пор } \\
\text { по диаметру, \% }\end{array}$} \\
\hline & вода & бензол & & & & $2-50 \mathrm{HM}$ & $\begin{array}{l}\text { более } \\
50 \text { нм }\end{array}$ \\
\hline \multirow{3}{*}{$\begin{array}{l}60 \% \mathrm{NaY}+32 \% \mathrm{~K} Э-3+5 \% Б \mathrm{C} \\
60 \% \mathrm{NaY}+32 \% \mathrm{~K}-3+5 \% \\
\text { силикагель } \\
60 \% \mathrm{NaY}+32 \% \mathrm{~K} Э-3+5 \% \\
\text { аэросил }\end{array}$} & 0.30 & 0.32 & FAU & 98 & 2.7 & 67.2 & 32.8 \\
\hline & 0.30 & 0.32 & FAU & 98 & 2.6 & 66.2 & 33.8 \\
\hline & 0.30 & 0.32 & FAU & 98 & 2.8 & 66.4 & 33.6 \\
\hline
\end{tabular}

* Сосmaв $\mathrm{PC}: 2.2 \mathrm{Na}_{2} \mathrm{O} \cdot \mathrm{Al}_{2} \mathrm{O}_{3} \cdot 6.5 \mathrm{SiO}_{2} \cdot 155 \mathrm{H}_{2} \mathrm{O}$.

Таблица 3

Физико-химические свойства образцов, полученных кристаллизацией исходных гранул состава $60 \% \mathrm{NaY}+32 \%$ КЭ-3 + 5\% БС

\begin{tabular}{|c|c|c|c|c|c|c|c|c|c|}
\hline \multicolumn{3}{|c|}{$\begin{array}{l}\text { Состав реакционных } \\
\text { смесей, моль/моль }\end{array}$} & \multicolumn{2}{|c|}{$\begin{array}{c}\text { Равновесная адсорбци- } \\
\text { онная емкость }\left(\mathrm{cm}^{3} / \Gamma\right) \text { по } \\
\text { парам: }\end{array}$} & \multirow{2}{*}{$\begin{array}{c}\text { ФС } \\
\text { по данным } \\
\text { РФА }\end{array}$} & \multirow{2}{*}{$\begin{array}{l}\text { ОСК, } \\
\% \text { отн. }\end{array}$} & \multirow{2}{*}{$\begin{array}{c}\text { Прочность на } \\
\text { раздавливание, } \\
\text { кг } / \mathrm{Mм}^{2}\end{array}$} & \multicolumn{2}{|c|}{$\begin{array}{c}\text { Распределение пор } \\
\text { по диаметру, \%: }\end{array}$} \\
\hline $\begin{array}{l}\mathrm{Na}_{2} \mathrm{O} / \\
\mathrm{Al}_{2} \mathrm{O}_{3}\end{array}$ & $\begin{array}{l}\mathrm{SiO}_{2} / \\
\mathrm{Al}_{2} \mathrm{O}_{3} \\
\end{array}$ & $\begin{array}{r}\mathrm{H}_{2} \mathrm{O} / \\
\mathrm{Al}_{2} \mathrm{O}_{3} \\
\end{array}$ & вода & бензол & & & & $2-50 \mathrm{Hм}$ & $\begin{array}{l}\text { более } \\
50 \mathrm{Hм} \\
\end{array}$ \\
\hline 1.9 & 6.0 & 150 & 0.26 & 0.27 & FAU & 89 & 2.7 & 56.2 & 43.8 \\
\hline 2.2 & 6.5 & 155 & 0.30 & 0.32 & FAU & 98 & 2.7 & 67.2 & 32.8 \\
\hline 2.4 & 6.5 & 155 & 0.30 & 0.32 & FAU & 98 & 2.7 & 66.8 & 33.2 \\
\hline 2.6 & 6.5 & 155 & 0.30 & 0.32 & FAU & 98 & 2.6 & 68.1 & 31.9 \\
\hline 2.6 & 7.5 & 165 & 0.30 & 0.32 & FAU & 98 & 2.6 & 66.2 & 33.8 \\
\hline 3.2 & 7.5 & 165 & 0.26 & 0.26 & FAU+ PHI & 98 & 3.1 & 52.1 & 47.9 \\
\hline
\end{tabular}

Видно, что уменьшение мольного соотношения $\mathrm{Na}_{2} \mathrm{O} / \mathrm{Al}_{2} \mathrm{O}_{3}$ (табл. 3, обр. 1) приводит к снижению скорости кристаллизации, и, как следствие, к уменьшению степени кристалличности образца NaY-БС. Наоборот, увеличение мольного соотношения $\mathrm{Na}_{2} \mathrm{O} / \mathrm{Al}_{2} \mathrm{O}_{3}$ (табл. 3, обр. 6) позволяет увеличить скорость кристаллизации, но, согласно данным РФА, в составе образца после кристаллизации наблюдается рост примесной фазы филипсита, что приводит к снижению адсорбционных характеристик.

\section{Выводы}

1. Разработан способ синтеза цеолита $\mathrm{NaY}$ высокой степени кристалличности с развитой вторичной пористой структурой и прочностью на раздав-

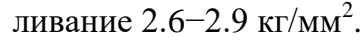

2. Установлено, что состав исходных гранул для синтеза цеолита $\mathrm{NaY}-Б \mathrm{C}$ должен строго соответствовать интервалам:

порошкообразный цеолит $\mathrm{NaY} \quad 55-70 \%$ масс.;

каолин

23-40\% мacc.;

«белая» сажа

(молотый силикагель или аэросил) 3-7\% масс.;

поливиниловый спирт

$2 \%$ мacc.

3. Выявлено, что в реакционной смеси мольное соотношение $\mathrm{Na}_{2} \mathrm{O} / \mathrm{Al}_{2} \mathrm{O}_{3}$ не должно превышать 2.6 , а мольное соотношение $\mathrm{SiO}_{2} / \mathrm{Al}_{2} \mathrm{O}_{3}$ должно находиться в интервале 6.5-7.5.

4. Обнаружено, что природа кремнесодержащего сырья, используемого при формировании исходных гранул, не влияет на адсорбционные и прочностные характеристики продуктов кристаллизации.

\section{ЛИТЕРАТУРА}

1. Cejka J., Corma A., Zones S. Zeolites and catalysis: synthesis, reactions and applications / Weinheim: Wiley-VCH, 2010. 880 p.

2. Degnan T. F. Recent progress in the development of zeolitic catalysts for the petroleum refining and petrochemical manufacturing industries // Studies in Surface Science and Catalysis. 2007. Vol. 170. P. 54-65.

3. Martínez C., Corma A. Coordination Inorganic molecular sieves: Preparation, modification and industrial application in catalytic processes // Chemistry Reviews. 2011. Vol. 255. P. $1558-1580$.

4. Vermeiren W., Gilson J.-P. Impact of zeolites on the petroleum and petrochemical industry // Top Catal. 2009. Vol. 52. P. 1131-1161

5. Басимова Р. А., Павлов М. Л., Герзелиев И. М. [и др.]; заявители и патентообладатели: ИНХС РАН, ООО «НТЦ Салаватнефтеоргсинтез». Катализатор, способ его получения и способ трансалкилирования бензола диэтилбензолами с его использованием. Патент РФ №2478429. МПК С07С6/12. заявл. 08.04.2012; опубл. 10.04.2013. 11 с.

6. Шавалеев Д. А., Павлов М. Л., Басимова Р. А. [и др.]; заявитель и патентообладатель ОАО «Газпром нефтехим Салават». Способ получения катализатора и способ трансалкилирования бензола диэтилбензолами с его использованием. Патент РФ №2553256. МПК В01J 29/08, В01J 37/30, В01J35/10, С07С 6/12. Заявл. 08.04.2014; опубл. 10.06.2015. $12 \mathrm{c}$.

7. Басимова Р. А., Павлов М. Л., Мячин С. И. [и др.]. Алкилирование бензола этиленом и трансалкилирование этилбензолов на цеолитных катализаторах // Нефтепереработка и нефтехимия. Научно-технические достижения и передовой опыт. 2008. №4-5. С. 94-96. 
8. Шавалеева Н. Н., Павлов М. Л., Басимова Р. А., Эрштейн А. С. Синтез ультрастабильного гранулированного без связующих веществ цеолита $\mathrm{Y}$ и на его основе катализатора трансалкилирования бензола диэтилбензолами // Нефтегазовое дело. 2013. Т. 11. №4. С. 158-164.

9. Эрштейн А. С., Шавалеева Н. Н., Шавалеев Д. А., Павлов М. Л., Басимова Р. А. Алкилирование бензола этиленом и этанэтиленовыми фракциями в присутствии катализатора USY-БС // Нефтегазовое дело. 2014. Т. 12. №4. С. 90.

10. Agliullin M. R., Danilova I. G., Faizullin A. V. et al. Sol-gel synthesis of mesoporous aluminosilicates with a narrow pore size distribution and catalytic activity thereof in the oligomerization of dec-1-ene // Microporous and Mesoporous Materials. 2016. Vol. 230. P. 118-127.

11. Muller K., Bein T., Mesoporosity - a new dimension for zeolites // Chem. Soc. Rev. 2013. Vol. 42. P. 3689-3707.

12. Chal R., Gerardin C., Bulut M., Van Donk S., Overview and Industrial Assessment of Synthesis Strategies towards Zeolites with Mesopores // Chem. Cat. Chem. 2011. Vol. 3. P. 67-81.

13. Wan Y. and Zhao D., On the Controllable Soft-Templating Approach to Mesoporous Silicates // Chemical Reviews. 2007. Vol. 107. P. 2821-2860.

14. Павлов М. Л., Травкина О. С., Кутепов Б. И. [и др.]; патентообладатель ФГБУ науки Институт нефтехимии и катализа РАН. Способ получения гранулированного без связующего цеолита NaY. Патент РФ №2540086. МПК С01B 39/24; В01Ј 29/08. Заявл. 06.08 2013; опубл. 27.01.2015. 10 с.

15. Шавалеев Д. А., Павлов М. Л., Басимова Р. А. [и др.]; заявитель и патентообладатель ОАО «Газпром нефтехим Салават». Способ получения гранулированного без свя- зующих веществ высокомодульного фожазита. Патент РФ №2557610. МПК С01В 39/24. Заявл. 08.04 2014; опубл. 27.07.2015. $9 \mathrm{c}$

16. Шавалеев Д. А., Павлов М. Л., Басимова Р. А. [и др.]; заявитель и патентообладатель ООО «НТЦ Салаватнефтеоргсинтез». Способ получения высокомодульного фожазита без связующих веществ. Патент РФ №2553876. МПК В01Ј29/08. заявл. 08.04.2014; опуб. 10.06.2015. 14 с.

17. Шавалеев Д. А., Павлов М. Л., Басимова Р. А. [и др.]; патентообладатель ООО «НТЦ Салаватнефтеоргсинтез». Способ получения гранулированного без связующего цеолита типа $\mathrm{NaY}$ высокой фазовой чистоты. Патент РФ №2568219. МПК С01В 39/24. Заявл. 08.04.2014; опубл. 10.11.2015. $11 \mathrm{c}$.

18. Павлов М. Л., Басимова Р. А., Шавалеев Д. А., Павлова И. Н., Травкина О. С., Алехина И. Е. // Синтез и исследование катализаторов жидкофазного алкилирования бензола этиленом на основе цеолита Ү без связующих // Вестник Башкирского университета. 2019. Т. 24. №2. C. $360-366$.

19. Павлов М. Л., Басимова Р. А., Каримов Р. А., Павлова И. Н., Алехина И. Е. Биоцеолитный катализатор для процесса гидропарафинизации углеводородных фракций // Вестник Башкирского университета. 2019. Т. 24. №4. C. $814-817$.

20. Плаченов Т. Г., Колосенцев С. Д. Порометрия. Л.: Химия. 1988. $175 \mathrm{c}$.

21. Кельцев Н. В. Основы адсорбционной техники. М.: Химия. 1984. 592 с.

Поступила в редакиию 09.02.2020 2. После доработки - 27.02.2020 2. 
DOI: 10.33184/bulletin-bsu-2020.1.15

\title{
SYNTHESIS OF GRANULATED NAY ZEOLITE WITH HIGH DEGREE OF CRYSTALLINITY
}

\author{
(C) D. A. Shavaleev' ${ }^{1}$, M. L. Pavlov ${ }^{2}$, R. A. Basimova ${ }^{2}$, O. S. Travkina ${ }^{3,4}$, \\ I. N. Pavlova ${ }^{3,4}$, L. F. Gabduramanova ${ }^{4}$, I. E. Alekhina ${ }^{5}$ \\ ${ }^{1}$ SNH Group \\ 8 Gagarin Street, 453261 Salavat, Republic of Bashkortostan, Russia. \\ ${ }^{2}$ Scientific and Technical Center Gazprom Neftehim Salavat \\ 30 Molodogvardeitsev Street, 453256 Salavat, Republic of Bashkortostan, Russia. \\ ${ }^{3}$ Institute of Petrochemistry and Catalysis of RAS \\ 141 Oktyabrya Avenue, 450075 Ufa, Republic of Bashkortostan, Russia. \\ ${ }^{4}$ Ufa State Petroleum Technological University \\ 1 Kosmonavtov Street, 450062 Ufa, Republic of Bashkortostan, Russia. \\ ${ }^{5}$ Bashkir State University \\ 32 Zaki Validi Street, 450076 Ufa, Republic of Bashkortostan, Russia.
}

*Email:28pml@snos.ru

\begin{abstract}
A method was developed for the synthesis of granulated zeolite $\mathrm{NaY}$ with high degree of crystallinity, developed porous structure, mechanical strength of $2.5-2.9 \mathrm{~kg} / \mathrm{mm}^{2}$, and having an adsorption capacity comparable to the adsorption capacity of a powdery zeolite of the same structural type. The method is based on hydrothermal crystallization of granules obtained by mixing powdered zeolite $\mathrm{NaY}$, kaolin, and fumed silica (silica gel or aerosil) from reaction mixtures of the following composition: (2.2-2.6) $\mathrm{Na}_{2} \mathrm{O} \cdot \mathrm{Al}_{2} \mathrm{O}_{3} \cdot(6.5-$ 7.5) $\mathrm{SiO}_{2} \cdot(155-165) \mathrm{H}_{2} \mathrm{O}$ at a temperature of $98-100{ }^{\circ} \mathrm{C}$ for 48 hours. The crystallization stage was preceded by the stage of preliminary exposure of the granules at a temperature of $25-30{ }^{\circ} \mathrm{C}$ for $12-24$ hours. The composition of the initial granules should strictly correspond to the intervals: NaY zeolite $55-70 \%$ by mass, kaolin $23-40 \%$ by mass, fumed silica (silica gel or aerosil) $3-7 \%$ by mass. It was found that going beyond the established intervals of both the composition of the initial granules and the reaction mixture leads to a decrease in performance and, accordingly, the quality of the product. It was revealed that the nature of the silicon-containing raw materials used in the formation of the initial granules does not affect the adsorption and strength characteristics of crystallization products.
\end{abstract}

Keywords: zeolite NaY, crystallization, high degree of crystallinity, adsorption capacity, mechanical strength.

Published in Russian. Do not hesitate to contact us at bulletin_bsu@mail.ru if you need translation of the article.

\section{REFERENCES}

1. Cejka J., Corma A., Zones S. Zeolites and catalysis: synthesis, reactions and applications / Weinheim: Wiley-VCH, 2010.

2. Degnan T. F. Studies in Surface Science and Catalysis. 2007. Vol. 170. Pp. 54-65.

3. Martínez C., Corma A. Chemistry Reviews. 2011. Vol. 255. Pp. 1558-1580.

4. Vermeiren W., Gilson J.-P. Top Catal. 2009. Vol. 52. Pp. 1131-1161.

5. Basimova R. A., Pavlov M. L., Gerzeliev I. M. [i dr.]; zayaviteli i patentoobladateli: INKhS RAN, OOO «NTTs Salavatnefteorgsintez». Katalizator, sposob ego polucheniya i sposob transalkilirovaniya benzola dietilbenzolami s ego ispol'zovaniem. Patent RF No. 2478429. MPK Pp. 7C6/12. zayavl. 08.04.2012; opubl. 10.04.2013.

6. Shavaleev D. A., Pavlov M. L., Basimova R. A. [i dr.]; zayavitel' i patentoobladatel' OAO «Gazprom neftekhim Salavat». Sposob polucheniya katalizatora i sposob transalkilirovaniya benzola dietilbenzolami s ego ispol'zovaniem. Patent RF No. 2553256. MPK B01J 29/08, B01J 37/30, B01J35/10, Pp. 7C 6/12. Zayavl. 08.04.2014; opubl. 10.06.2015.

7. Basimova R. A., Pavlov M. L., Myachin S. I. [i dr.]. Alkilirovanie benzola etilenom i transalkilirovanie etilbenzolov na tseolitnykh katalizatorakh. Neftepererabotka i neftekhimiya. Nauchno-tekhnicheskie dostizheniya i peredovoi opyt. 2008. No. 4-5. Pp. 94-96.

8. Shavaleeva N. N., Pavlov M. L., Basimova R. A., Ershtein A. S. Neftegazovoe delo. 2013. Vol. 11. No. 4. Pp. $158-164$.

9. Ershtein A. S., Shavaleeva N. N., Shavaleev D. A., Pavlov M. L., Basimova R. A. Neftegazovoe delo. 2014. Vol. 12. No. 4. Pp. 90.

10. Agliullin M. R., Danilova I. G., Faizullin A. V. Microporous and Mesoporous Materials. 2016. Vol. 230. Pp. $118-127$. 
11. Muller K., Bein T. Chem. Soc. Rev. 2013. Vol. 42. Pp. 3689-3707.

12. Chal R., Gerardin C., Bulut M., Van Donk S. Chem. Cat. Chem. 2011. Vol. 3. Pp. 67-81.

13. Wan Y. and Zhao D. Chemical Reviews. 2007. Vol. 107. Pp. 2821-2860.

14. Pavlov M. L., Travkina O. S., Kutepov B. I. [i dr.]; patentoobladatel' FGBU nauki Institut neftekhimii i kataliza RAN. Sposob polucheniya granulirovannogo bez svyazuyushchego tseolita NaY. Patent RF No. 2540086. MPK Pp. 1B 39/24; B01J 29/08. Zayavl. 06.08 2013; opubl. 27.01.2015.

15. Shavaleev D. A., Pavlov M. L., Basimova R. A. [i dr.]; zayavitel' i patentoobladatel' OAO «Gazprom neftekhim Salavat». Sposob polucheniya granulirovannogo bez svyazuyushchikh veshchestv vysokomodul'nogo fozhazita. Patent RF No. 2557610. MPK Pp. 1B 39/24. Zayavl. 08.04 2014; opubl. 27.07.2015.

16. Shavaleev D. A., Pavlov M. L., Basimova R. A. [i dr.]; zayavitel' i patentoobladatel' OOO «NTTs Salavatnefteorgsintez». Sposob polucheniya vysokomodul'nogo fozhazita bez svyazuyushchikh veshchestv. Patent RF No. 2553876. MPK B01J29/08. zayavl. 08.04.2014; opub. 10.06.2015.

17. Shavaleev D. A., Pavlov M. L., Basimova R. A. [i dr.]; patentoobladatel' OOO «NTTs Salavatnefteorgsintez». Sposob polucheniya granulirovannogo bez svyazuyushchego tseolita tipa NaY vysokoi fazovoi chistoty. Patent RF No. 2568219. MPK Pp. 1B 39/24. Zayavl. 08.04.2014; opubl. 10.11.2015.

18. Pavlov M. L., Basimova R. A., Shavaleev D. A., Pavlova I. N., Travkina O. S., Alekhina I. E. Vestnik Bashkirskogo universiteta. 2019. Vol. 24. No. 2. Pp. 360-366.

19. Pavlov M. L., Basimova R. A., Karimov R. A., Pavlova I. N., Alekhina I. E. Vestnik Bashkirskogo universiteta. 2019. Vol. 24. No. 4. Pp. 814-817.

20. Plachenov T. G., Kolosentsev S. D. Porometriya [Porometry]. Leningrad: Khimiya. 1988.

21. Kel'tsev N. V. Osnovy adsorbtsionnoi tekhniki [The basics of adsorption technology]. Moscow: Khimiya. 1984.

Received 09.02.2020.

Revised 27.02.2020. 